\title{
Laparoscopic Gastrectomy for Cancer
}

\author{
Tsuyoshi Etoh Norio Shiraishi Seigo Kitano \\ Department of Surgery I, Oita University Faculty of Medicine, Oita, Japan
}

\section{Key Words}

Laparoscopy-assisted distal gastrectomy - Early gastric cancer $\cdot$ Surgical outcome

\begin{abstract}
There are three procedures for the management of early gastric cancer (EGC): laparoscopic wedge resection (LWR), intragastric mucosal resection (IGMR), and laparoscopic gastrectomy. LWR or IGMR can be applied to treat EGC without the risk of lymph node metastasis. However, owing to the recent technical advances in endoscopic mucosal resection for EGC, the use of laparoscopic local resection for these lesions has gradually decreased. On the other hand, laparoscopic gastrectomy with lymph node dissection, such as laparoscopy-assisted distal gastrectomy, is widely accepted for the treatment of EGC with the risk of lymph node metastasis. To establish the acceptability of laparoscopic gastrectomy with D2 lymph node dissection against advanced gastric cancers, safe techniques and new instruments must be developed. The following advantages of laparoscopic surgery for the treatment of gastric cancer have been well demonstrated: clinical course after operation, pulmonary function, immune response. In the future, lapa-
\end{abstract}

roscopic surgeons have to design and implement education and training systems for standard laparoscopic procedures, evaluate clinical outcomes by multicentric randomized control trial studies, and clarify the oncological aspects of laparoscopic surgery in basic studies.

Copyright $\subset 2005$ S. Karger AG, Basel

\section{Introduction}

Gastric cancer has been one of the most common causes of cancer death in the world. Recently, the detection of early gastric cancer (EGC) has been increasing and new treatment strategies for gastric cancer have been developed. The 5-year survival rate of patients with EGC who underwent surgical treatment has reached $90 \%$ or more in Japan [1-3]. On the basis of the low incidence of node involvement in most EGC patients, current surgical trends for EGC have shifted from surgery with extended lymph node dissection to minimally invasive surgery, thereby providing a better postoperative quality of life.

Laparoscopic surgery has become popular as a minimally invasive procedure. The following advantages of laparoscopic surgery for the treatment of gastrointesti-

\section{KARGER}

Fax +4161306 1234

E-Mail karger@karger.ch

www.karger.com
C 2005 S. Karger AG, Basel

$0257-2753 / 05 / 0232-0113 \$ 22.00 / 0$

Accessible online at: www.karger.com/ddi
Tsuyoshi Etoh, MD

Department of Surgery I, Oita University Faculty of Medicine

Hasama-machi, Oita 879-5593 (Japan)

Tel. +81975865843, Fax +81975496039

E-Mail teto@med.oita-u.ac.jp 
nal disease including EGC have been well demonstrated: clinical course after operation, pulmonary function, immune response [4-7]. For the management of patients with EGC, laparoscopic gastrectomy has been widely accepted in Japan. Recently, the use of laparoscopic gastrectomy for advanced gastric cancer has been attempted. In this article, the authors review the literature on the indications, techniques, outcomes, and future perspective of laparoscopic gastrectomy for gastric cancer.

\section{Early Gastric Cancer}

\section{Incidence of Lymph Node Metastasis}

The most important factor influencing the survival of patients with EGC is the status of lymph node metastasis [8-11]. The incidences of lymph node metastasis in large series of EGC range from 1 to 3\% for tumors confined to the mucosa $[10,12,13]$ and from 11 to $20 \%$ for tumors invading the submucosa [12-14]. Lymph node metastasis is rare in patients with mucosal cancer, and is restricted mostly to the perigastric nodes in patients with node-positive EGC [12, 13, 15-17].

\section{Endoscopic Mucosal Resection for Early Gastric Cancer}

Although endoscopic mucosal resection (EMR) is a useful procedure for EGC without a risk of lymph node metastasis, a successful EMR requires the en bloc resection of the EGC. The Japanese Gastric Cancer Association issued the first version of its gastric cancer treatment guidelines in 2001. These guidelines indicate EMR for intestinal-type mucosal cancers that lack ulcerative findings and that are $<2 \mathrm{~cm}$ in diameter, regardless of tumor morphology [18]. Recently, several new devices for endoscopic submucosal dissection (ESD) have been developed, such as an insulation-tipped diathermic knife [19], a hook knife [20], a flex knife [21], and a triangle-tipped knife [22]. ESD enables us to completely remove a large lesion as a single fragment. However, as the frequency of complications during ESD is reported to be relatively higher than conventional EMR [19], endoscopists should obtain the skills needed to carry out ESD safely. When ESD is safely and commonly performed, all intestinaltype mucosal cancers without ulcerative findings will be indicated for ESD.
Laparoscopic Gastrectomy for Early Gastric Cancer

Current Trends in Laparoscopic Gastrectomy

There are three procedures for the management of EGC: (1) laparoscopic wedge resection (LWR) [23, 24], (2) intragastric mucosal resection (IGMR) [25], and (3) laparoscopic gastrectomy (totally laparoscopic, laparoscopy-assisted, and hand-assisted). Since our first experience doing laparoscopy-assisted distal gastrectomy (LADG) by a Billroth I reconstruction for a patient with EGC in 1991 [26], a national survey conducted by the Japan Society of Endoscopic Surgery (JSES) showed increasing use of laparoscopic procedures for EGC in Japan. During the period from 1991 to 2004, 7,827 patients underwent laparoscopic surgery for gastric cancer [27]. Along with the societal recognition of the significance of minimally invasive surgery for EGC, the popularity of LADG with lymph node dissection has increased rapidly, and this procedure now accounts for about $83 \%$ of all laparoscopic surgeries for gastric cancer in Japan. LADG was reported to have several advantages over open surgery, including earlier recovery and better patient's quality of life [4-7].

Several recent studies have evaluated the validity of the sentinel node $(\mathrm{SN})$ concept for the treatment of gastric cancer as well as malignant melanoma or breast cancer [28-31]. Now, two major, well-designed, large-scale clinical trials to clarify the validity of the SN concept for gastric cancer have been conducted by two Japanese groups: the Japan Clinical Oncology Group and the Japan Society of Sentinel Node Navigation Surgery. Although laparoscopic detection and sampling for SNs of gastric cancer is believed to be more technically difficult than open surgery [28], the SN navigation concepts must contribute to the choice of surgical treatments for EGC, including EMR and laparoscopic surgery.

\section{Indication of Laparoscopic Gastrectomy for Early}

\section{Gastric Cancer}

Most early cancers are located only in the gastric wall, and local resection of the gastric wall is adequate for complete clearance. Theoretically, laparoscopic local resection, such as LWR or IGMR, can be applied to treat EGC without the risk of lymph node metastasis. However, owing to the recent technical advances in EMR for EGC, the use of laparoscopic local resection for these lesions has gradually decreased. On the other hand, laparoscopic gastrectomy with lymph node dissection, such as LADG, has been widely accepted to treat EGC with the risk of lymph node metastasis [32]. 
Since it is difficult to diagnose lymph node metastasis preoperatively, the risk for it is estimated by the tumor size, the depth of cancer invasion, the presence of ulceration, and the histological type. On the basis of pathological findings in a large number of surgically resected specimens, the Japanese Gastric Cancer Association guidelines recommend the following optimal lymph node dissection levels for EGC: D1 $+\alpha$ (perigastric lymph node dissection) for mucosal cancer, for which EMR is not indicated and for histologically differentiated submucosal cancer of $<1.5 \mathrm{~cm}$ in diameter; $\mathrm{D} 1+\beta$ for preoperatively diagnosed submucosal cancer without lymph node metastasis (N0), for which $\mathrm{D} 1+\alpha$ is not indicated, and for early cancer $<2.0 \mathrm{~cm}$ in diameter with only perigastric lymph node metastasis (N1); D2 for early cancer $>2.0 \mathrm{~cm}$ in diameter, with lymph node positive. According to these guidelines, lymph node dissection is performed in LADG.

\section{Surgical Techniques of LADG}

The techniques of LADG are described below [26]. The essentials for LADG with D1+ $\alpha$ lymph node dissection for gastric cancer are as follows: (1) Under general anesthesia, a $10-\mathrm{mm} \mathrm{Hg}$ pneumoperitoneum is created and a laparoscope is inserted through the subumbilical incision. (2) Four cannulas for grasping and dissecting instruments are placed in the upper abdomen. (3) The greater omentum and gastrocolic ligament are dissected laparoscopically outside the epigastric arcade. (4) The right gastroepiploic vessels are cut to facilitate dissection of the lymph nodes at the subpyloric portion. (5) The lesser omentum is opened and the suprapyloric lymph nodes are dissected after the right gastric artery and vein are divided between clips. (6) The stomach is fully mobilized, and the left gastric artery and vein are divided using clips. (7) The left cardiac and superior gastric lymph nodes are dissected down to the distal portion of the stomach. (8) A 5-cm long upper laparotomy is made just below the xiphoid, and the mobilized stomach is pulled out through this minilaparotomy wound. The distal twothirds of the stomach is resected using staplers. (9) Billroth I gastroduodenostomy is carried out through the minilaparotomy wound, with the same handsewn technique as used for conventional open surgery.

Comparison of Short-Term Outcome between

LADG and Conventional Open Gastrectomy for EGC

Several studies about the short-term outcome of LADG for EGC have been reported. With regard to op- erative findings, several studies have demonstrated a longer operation time and lower blood loss for LADG than for open distal gastrectomy (ODG) [33]. But, the learning curves of surgical teams suggested that training reduced the operation time for LADG [5, 34].

There have been several comparative studies of surgical morbidity between LADG and ODG. Most of those studies demonstrated the same or lower incidence of complications associated with LADG as with ODG [5, 33, 34]. According to the JSES survey, the morbidity and mortality associated with LADG were 9.7 and $0 \%$, respectively. These results suggest that LADG is a safe procedure. Even in obese patients, morbidity and length of hospital stay were not increased, although LADG required a longer operating time for obese patients than for non-obese patients $[35,36]$.

Several studies on the lower invasiveness of LADG relative to ODG demonstrated several advantages of LADG, as follows. Prospective and retrospective analyses by a single institution showed earlier recovery of bowel function after LADG than after ODG [6, 37]. Also, in several studies, pain was reported to be significantly less after LADG than after ODG [6, 7]. LADG offers particular advantages to elderly patients with EGC, including rapid return of gastrointestinal function, fewer complications, and a shorter hospital stay [38]. Other shortterm advantages of LADG were demonstrated by a randomized trial with a small sample at a single institution, which revealed better postoperative pulmonary function after LADG than ODG because there was less pain after the former [39].

Regarding the cost, a case-controlled study reported that LADG is less expensive than conventional open gastrectomy because the hospital stay is shorter [40, 41].

\section{Evaluation of Long-Term Results of LADG}

Although most retrospective published studies were composed of a small number of patients and showed short-term follow-up [39, 42-46], there have been few studies about the long-term outcome of LADG [47]. Indeed there is only one prospective randomized trial (RCT) about the long-term outcome of LADG. Huscher et al. [48] reported 5-year postoperative results by RCT with a small series comparing LADG with ODG for gastric cancer. Those authors found no significant difference in operative morbidity or mortality, 5-year overall, or diseasefree survival between the two groups. In the near future, a multicenter randomized controlled trial is needed to confirm the long-term advantages of LADG for gastric cancer. 
Other Laparoscopic Gastrectomies for EGC

Laparoscopic distal, proximal, and total gastrectomies are performed according to the location of the tumor, as with open surgery. Laparoscopic proximal and total gastrectomies are indicated for EGC located at the upper stomach [49-53]. In both of these procedures, how to make reconstruction laparoscopically is a problem. Furthermore, to preserve the function of the gastric remnant after gastrectomy, a laparoscopic pylorus-preserving gastrectomy without injuring vagal nerves such as the pyloric or hepatic branch was tried [54].

\section{Advanced Gastric Cancer}

D2 lymph node dissection in which the lymph nodes in the first (perigastric) and second (along the celiac artery and its branches) tiers are dissected is widely accepted in Japan for the treatment of advanced gastric cancer. A study of Japanese experience found that $30-40 \%$ of patients with metastasis in even second-tier lymph nodes who underwent D2 lymph node dissection have survived more than 5 years [55]. However, surgeons in the USA and other Western countries rarely perform extensive prophylactic lymphadenectomy, because two European randomized trials (RCT) showed no survival advantage of D2 over D1. Since these trials also compared D1 and D2 and showed high operative mortality in the latter - exceeding 10\% - the British NHS Cancer Guidance officially discourages the use of D2 in clinical practice [56, 57].

According to the JSES survey, D1+ $\alpha$ lymph node dissection was performed in $67 \%$ and D2 lymph node dissection in 23\% of LADGs for gastric cancer in Japan. Several investigators reported low mortality and morbidity in laparoscopic D2 lymph node dissection [58-60]. More recently, RCT by Huscher et al. [48] demonstrated the feasibility and safety of laparoscopic subtotal gastrectomy with D2 lymph node dissection for advanced gastric cancer. However, laparoscopic D2 lymph node dissection requires a learning curve, as does conventional open surgery. To establish the acceptability of laparoscopic gastrectomy with D2 lymph node dissection against advanced gastric cancers, safe techniques and new instruments must be developed.

\section{Future Aspects}

To establish laparoscopic surgery as a standard treatment for gastric cancer, several issues must be resolved. The first is the prevalence of standard techniques, and the development of education and training systems is important. Recently, several training machines and animal training centers for getting better laparoscopic techniques have been developed. In addition, the JSES has started to design a Board Certification Examination for laparoscopic procedures. Thus, with the aim of popularizing laparoscopic surgery, education and training in standard laparoscopic techniques continue to develop.

The second issue is the evaluation of long-term outcome of laparoscopic gastrectomy for gastric cancer. Since laparoscopic gastrectomy for gastric cancer has been shown to be potentially superior in short-term outcome to open surgery, multicenter, large-scale randomized trials are required in order to establish laparoscopic gastrectomy not only for EGC but also for advanced gastric cancer.

Third, the oncological aspects of the influence of $\mathrm{CO}_{2}$ pneumoperitoneum should be elucidated. So far, the effects of $\mathrm{CO}_{2}$ pneumoperitoneum on cancer growth and progression, including lymph node metastasis and both hematogenous and peritoneal dissemination, have been reported in animal models [61-63]. $\mathrm{CO}_{2}$ pneumoperitoneum in laparoscopic surgery has been reported to be inferior to laparotomy in open surgery regarding the activation of the spread of cancers except liver metastasis [64]. To better evaluate the oncological aspects of laparoscopic surgery, further examination of the effects of $\mathrm{CO}_{2}$ pneumoperitoneum on cancer progression are needed.

Thus, laparoscopic surgeons have to design and implement education and training systems for standard laparoscopic procedures, evaluate clinical outcomes by multicentric RCT studies, and clarify the oncological aspects in basic studies. Laparoscopic surgeons expect that laparoscopic gastrectomy with minimal invasiveness will become a worldwide standard procedure for the treatment of gastric cancer. 


\section{References}

1 Matsukura A, Furusawa M, Tomoda H, et al: A clinicopathological study of asymptomatic gastric cancer. Br J Cancer 1996;74:16471650.

2 Kubota H, Kotoh T, Masunaga R, et al: Impact of screening survey of gastric cancer of clinicopathological features and survival: retrospective study at a single institution. Surgery 2000; 128:41-47.

-3 Adachi Y, Mori M, Maehara Y, et al: Prognostic factors of node-negative gastric carcinoma: univariate and multivariate analyses. J Am Coll Surg 1997; 184:373-377.

-4 Azagra JS, Goergen M, De Simone P, et al: The current role of laparoscopic surgery in the treatment of benign gastroduodenal diseases. Hepatogastroenterology 1999,46:1522-1526.

5 Yano H, Monden T, Kinuta M, et al: The usefulness of laparoscopy-assisted distal gastrectomy in comparison with that of open distal gastrectomy for early gastric cancer. Gastric Cancer 2001,4:93-97

6 6 Shimizu S, Noshiro H, Nagai E, et al: Laparoscopic gastric surgery in a Japanese institution: analysis of the initial 100 procedures. J Am Coll Surg 2003,197:372-378.

7 Adachi Y, Suematsu T, Shiraishi N, et al: Quality of life after laparoscopy-assisted Billroth I gastrectomy. Ann Surg 1999,229:49-54.

-8 Maruyama K: The most important prognostic factors for gastric cancer patients: a study using univariate and multivariate analyses. Scand J Gastroenterol Suppl 1987;22:63-68.

9 Okajima K: Prognostic factors of gastric cancer patients: a study by univariate and multivariate analysis (in Japanese/English abstract). Jpn J Gastroenterol Surg 1997;30:700-711.

10 Kunisaki C, Shimada H, Takahashi M, et al: Prognostic factors in early gastric cancer. Hepatogastroenterology 2001;48:294-298.

- 11 Isozaki H, Tanaka N, Okajima K: General and specific prognostic factors of early gastric carcinoma treated with curative surgery. Hepatogastroenterology 1999;46:1800-1808.

-12 Nakamura K, Morisaki T, Sugitani A, et al: An early gastric carcinoma treatment strategy based on analysis of lymph node metastasis. Cancer 1999;85;1500-1505.

$\checkmark 13$ Namieno T, Koito K, Higashi T, et al: Assessing the suitability of gastric carcinoma for limited resection: endoscopic prediction of lymph node metastases. World J Surg 1998;22:859_ 864.

14 Gotoda T, Yanagisawa A, Sasako M, et al: Incidence of lymph node metastasis from early gastric cancer: estimation with a large number of cases at two large centers. Gastric Cancer 2000;3:219-225.

$\checkmark 15$ Kunisaki C, Shimada H, Nomura M, et al: Appropriate lymph node dissection for early gastric cancer based on lymph node metastases. Surgery 2001;129:153-157.
16 Korenaga D, Haraguchi M, Tsujitani S, et al: Clinicopathological features of mucosal carcinoma of the stomach with lymph node metastasis in eleven patients. Br J Surg 1986; 73:431433.

17 Iriyama K, Asakawa T, Koike H, et al: Is extensive lymphadenectomy necessary for surgical treatment of intramucosal carcinoma of the stomach? Arch Surg 1989;124:309-311.

18 The Japanese Gastric Cancer Association: Guidelines for the treatment of gastric cancer. Tokyo, Kanehara-Shuppann, 2001.

19 Ono H, Kondo H, Gotoda T, et al: Endoscopic mucosal resection for treatment of early gastric cancer. Gut 2001;48:225-229.

20 Oyama T, Hotta Y, Hirasawa, et al: Endoscopic submucosal resection using a hook knife (abstract in Japanese). Gastrointest Endosc 2003; 45:1525.

21 Yahagi N, Fujishiro M, Kakushima N, et al: Endoscopic submucosal dissection for early gastric cancer using the tip of an electro-surg snare (thin type). Dis Endosc 2004;16:34-38.

22 Inoue $\mathrm{H}, \mathrm{Kudo} \mathrm{S}$ : A novel procedure of en bloc EMR using triangle-tipped knife (abstract) Gastrointest Endosc 2003;57:494.

23 Ohgami M, Otani Y, Kumai K, et al: Curative laparoscopic surgery for early gastric cancer: five years' experience. World J Surg 1999;23: 187-193.

24 Altorjay A, Szanto I, Garcia J, et al: Endoscope-assisted laparoscopic resection of the gastric wall. Orv Hetil 1996;137:2743-2745.

25 Ohashi S: Laparoscopic intraluminal (intragastric) surgery for early gastric cancer. A new concept in laparoscopic surgery. Surg Endosc 1995,9:169-171.

26 Kitano S, Iso Y, Moriyama M, et al: Laparoscopy-assisted Billroth I gastrectomy. Surg Laparosc Endosc 1994;4:146-148.

27 Japan Society for Endoscopic Survey: Nationwide survey on endoscopic surgery in Japan. J Jpn Soc Endosc Surg 2004;9:491-499.

28 Kitagawa Y, Fujii H, Mukai M, et al: Radioguided sentinel node detection for gastric cancer. Br J Surg 2002;89:604-608.

-29 Miwa K, Kinami S, Taniguchi K, et al: Mapping sentinel nodes in patients with early-stage gastric carcinoma. Br J Surg 2003;90:178182.

30 Reintgen D, Cruse CW, Wells K, et al: The ordinary progression of melanoma nodal metastases. Ann Surg 1994;220:759-767.

31 Veronesi U, Paganelli G, Galimberti V, et al: Sentinel-node biopsy to avoid axillary dissection in breast cancer with clinically negative lymph nodes. Lancet 1997;349:1864-1867.

32 Kitano S, Shiraishi N: Minimally invasive surgery for gastric tumors. Surg Clin N Am 2005; 85:151-164.

33 Mochiki E, Nakabayashi T, Kamimura H, et al: Gastrointestinal recovery and outcome after laparoscopy-assisted versus conventional open distal gastrectomy for early gastric cancer. World J Surg 2002;26:1145-1149.
34 Adachi Y, Shiraishi N, Shiromizu A, et al: Laparoscopy assisted Billroth I gastrectomy compared with conventional open gastrectomy. Arch Surg 2000;135:806-810.

35 Yasuda K, Inomata M, Shiraishi N, et al: Laparoscopy-assisted distal gastrectomy for early gastric cancer in obese and nonobese patients. Surg Endosc 2004,18:1253-1256.

- 36 Noshiro H, Shimizu S, Nagai E, et al: Laparoscopy-assisted distal gastrectomy for early gastric cancer: is it beneficial for patients of heavier weight? Ann Surg 2003;238:680-685.

37 Schwenk W, Bohm B, Muller JM: Postoperative pain and fatigue after laparoscopic or conventional colorectal resections. A prospective randomized trial. Surg Endosc 1998;12:11311136.

38 Yasuda K, Sonoda H, Shiroshita M, et al: Laparoscopically assisted distal gastrectomy for early gastric cancer in the elderly. Br J Surg 2004,91:1061-1065.

39 Kitano S, Shiraishi N, Fujii K, et al: A randomized controlled trial comparing open vs. laparoscopy-assisted distal gastrectomy for the treatment of early gastric cancer: an interim report. Surgery 2002;131:S306-S311.

40 Adachi Y, Shiraishi N, Ikebe K, et al: Evaluation of the cost for laparoscopic-assisted Billroth I gastrectomy. Surg Endosc 2001;15:932936.

41 Rosin D, Brasesco O, Rosenthal RJ: Laparoscopy for gastric tumors. Surg Oncol Clin N Am 2001;10:511-529.

42 Reyes CD, Weber KJ, Gagner M, et al: Laparoscopic vs. open gastrectomy. A retrospective review. Surg Endosc 2001;15:928-931.

-43 Tanimura S, Higashino M, Fukunaga Y, et al: Laparoscopic gastrectomy with regional lymph node dissection for upper gastric cancer. Gastric Cancer 2003;6:64-68.

44 Azagra JS, Goergen M, De Simone P, et al: Minimally invasive surgery for gastric cancer. Surg Endosc 1999;13:351-357.

45 Huscher CG, Anastasi A, Crafa F, et al: Laparoscopic gastric resections. Semin Laparose Surg 2000;7:26-54.

46 Ballesta Lopez C, Ruggiero R, Poves I, et al: The contribution of laparoscopy to the treatment of gastric cancer. Surg Endosc 2002;16: 616-619.

47 Kitano S, Shiraishi N, Kakisako K, et al: Laparoscopy-assisted Billroth-I gastrectomy (LADG) for cancer: our 10 years' experience. Surg Laparosc Endosc Percutan Tech 2002;12: 204-207.

48 Huscher CG, Mingoli A, Sgarzini G, et al: Laparoscopic versus open subtotal gastrectomy for distal gastric cancer: five-year results of a randomized prospective trial. Ann Surg 241:232237.

49 Asao T, Hosouchi Y, Nakabayashi T, et al: Laparoscopically assisted total or distal gastrectomy with lymph node dissection for early gastric cancer. Br J Surg 2001;88:128-132. 
50 Ikeda Y, Sasaki Y, Niimi M, et al: Hand-assisted laparoscopic proximal gastrectomy with jejunal interposition and lymphadenectomy. J Am Coll Surg 2002;195:578-581.

-51 Mochiki E, Nakabayashi T, Kamimura H, et al: Gastrointestinal recovery and outcome after laparoscopy-assisted versus conventional open distal gastrectomy for early gastric cancer. World J Surg 2002;26:1145-1149.

$\checkmark 52$ Tanimura S, Higashino M, Fukunaga Y, et al: Laparoscopic gastrectomy with regional lymph node dissection for upper gastric cancer. Gastric Cancer 2003;6:64-68.

53 Kim YW, Han HS, Fleischer GD: Hand-assisted laparoscopic total gastrectomy. Surg Laparosc Endosc Percutan Tech 2003;13:2630.

54 Horiuchi T, Shimomatsuya T, Chiba Y: Laparoscopically assisted pylorus-preserving gastrectomy. Surg Endosc 2001;15:325-328.

55 Sasako M, McCulloch P, Kinoshita T, et al: New method to evaluate the therapeutic value of lymph node dissection for gastric cancer. $\mathrm{Br}$ J Surg 1995;82:346-351.
56 Bonenkamp JJ, Songun I, Hermans J, et al: Randomised comparison of morbidity after D1 and D2 dissection for gastric cancer in 996 Dutch patients. Lancet 1995;345:745-748.

57 Cuschieri A, Fayers P, Fielding J, et al: Postoperative morbidity and mortality after D1 and D2 resections for gastric cancer: preliminary results of the MRC randomised controlled surgical trial. The Surgical Cooperative Group. Lancet 1996;347:995-999.

58 Tanimura S, Higashino M, Fukunaga Y, et al: Hand-assisted laparoscopic distal gastrectomy with regional lymph node dissection for gastric cancer. Surg Laparosc Endosc Percutan Tech 2001;11:155-160.

59 Uyama I, Sugioka A, Matsui H, et al: Laparoscopic D2 lymph node dissection for advanced gastric cancer located in the middle or lower third portion of the stomach. Gastric Cancer $2000 ; 3: 50-55$.
60 Goh PM, Khan AZ, So JB, et al: Early experience with laparoscopic radical gastrectomy for advanced gastric cancer. Surg Laparosc Endosc Percutan Tech 2001;11:83-87.

61 Canis M, Botchorishvili R, Wattiez A, et al: Tumor growth and dissemination after laparotomy and $\mathrm{CO}_{2}$ pneumoperitoneum: a rat ovarian cancer model. Obstet Gynecol 1998; 92:104-108.

62 Gutt CN, Kim ZG, Schmandra T, et al: Carbon dioxide pneumoperitoneum is associated with increased liver metastases in a rat model. Surgery 2000; 127:566-570.

63 Ishida H, Idezuki Y, Yokoyama M, et al: Liver metastasis following pneumoperitoneum with different gases in a mouse model. Surg Endosc 2001;15:189-192.

64 Shiromizu A, Suematsu T, Yamaguchi K, et al: Effect of laparotomy and laparoscopy on the establishment of lung metastasis in a murine model. Surgery 2000;128:799-805. 